The section on stereotactic spinal radiosurgery is cursory and out of place in this text and a section on kyphoplasty/ vertebroplasty would have been more useful. I thought the chapter on the MI treatment of lumbar stenosis to be the most useful in the book with some details and expert advice provided.

As a moderately experienced MI spinal surgeon, to whom I have suggested this text is targeted, at the end of reading it I found myself struggling to identify anything particularly useful I may have learned. I was continuously frustrated by the lack of examples and expert advice and complication avoidance sections. I suppose I learned one or two details regarding MI lumbar decompressions and perhaps I have been inspired to seek more advice and training for MI lateral mass screws in the cervical spine. I don't think it is enough to have me say that this book is required or even suggested reading for the aspiring or accomplished MI spinal surgeon.

Stephen J. Hentschel Victoria, British Columbia, Canada
Tuberous Sclerosis Complex. Genes, Chinical Features, AND Therapeutics. 2010. Edited by: David J. Kwiatkowski, Vicki Holets Whittemore, Elizabeth A. Thiele. Published by Wiley-Blackwell. 409 pages. C\$120 approx.

\section{Rated corats}

This is an amazing collection of all the latest information on this not uncommon neurocutaneous disorder.

The early chapters on genetics and

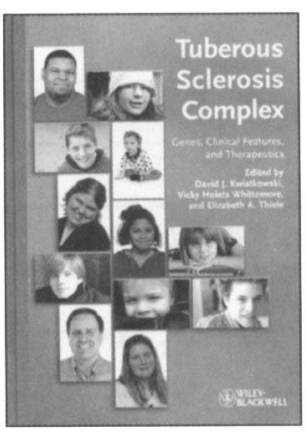
molecular mechanism of Tuberous Sclerosis (TS) are comprehensive and gather together in one place a lot of basic science information from various laboratories, these chapters are well referenced. They make fairly heavy going for a clinician but things improve after the first 160 pages when the chapters are devoted to clinical entities like Epilepsy in TS, subependymal giant cell astrocytomas, cognitive and psychological aspects of TS.

The last part of this book contains less extensive information on ophthalmologic, cardiac, pulmonary, dermatological and renal manifestations.

Throughout there are excellent clinical photographs, superb pictures of gross and microscopic pathology and clear examples from EEG and imaging.

All in all this is an amazing collection of current information on Tuberous Sclerosis and is relatively well priced for such an expensively illustrated text. It makes an excellent source for recent information and is of interest to most people in the world of Pediatric Neurology. 